\title{
The Main Refrigeration Compressor di KM. Sabuk Nusantara 37 pada PT. Pelni
}

\author{
Erita $^{1 *}$, Syefli Ewimia Darza ${ }^{2}$, Ade Putra Kurniawan ${ }^{3}$, Nofrizal ${ }^{4}$ \\ ${ }^{1}$ Dosen Program Studi Pendidikan Akuntansi STKIP PGRI Sumatera Barat \\ ${ }^{2,3}$ Dosen Program Studi Teknika Akademi Maritim Sapta Samudra Padang \\ ${ }^{4}$ Mahasiswa Program Studi Nautika Akademi Maritim Sapta Samudra Padang \\ * Corresponding Author. E-mail : eritasyofyan4516@ gmail.com. Telp : 081363442779
}

\begin{abstract}
Abstrak
Dengan semakin berkembangnya teknologi serta kemajuan zaman pada saat ini ternyata sistem pendingin banyak memberikan keuntungan bagi manusia yang secara tidak sadar mungkin dapat kita rasakan selama ini. sistem pendinginan pada umumnya banyak digunakan untuk kepentingan industri dan komersial. Pada saat ini Refrigeration merupakan salah satu alat yang peranannya dalam kehidupan manusia saat ini bisa dibilang cukup besar. Refrigeration digunakan untuk menyimpan bahan-bahan makanan, sayuran bahkan buahbuahan. Penelitian dilakukan terhadap masalah atau kerusakan-kerusakan yang terjadi pada refrigeration di kapal KM Sabuk Nusantara 37 pada PT Pelni. Jenis penelitian yang digunakan dalam penulisan skripsi ini adalah jenis penelitian deskriptif, dengan menggunakan pendekatan kualitatif. Analisis data dilakukan dengan mengunakan metode deskriptif, yaitu metode yang dilakukan dengan terlebih dahulu mengumpulkan data yang ada kemudian diklasifikasikan, selanjutnya diinterprestasikan sehingga dapat memberikan pemecahan terhadap permasalahan. 8 masalah yang paling sering terjadi pada sistem refigeration di kapal KM. Sabuk Nusantara 37 yaitu kompressor jalan tapi berhenti tiba-tiba, Compressor terlalu sering start dan stop, Kompresor jalan terus menerus, Suara yang tidak biasa pada kompresor, Tingginya Temperatur Discharge, Bunga Es pada Evaporator, Kemampuan untuk mendinginkan yang berkurang, Berkurangnya oli dalam kompressor.
\end{abstract}

Kata Kunci: Refrigeration, Compressor

\begin{abstract}
With the development of technology and the progress of the times at this time it turns out that the cooling system provides many benefits for humans that we may unconsciously feel so far. cooling systems are generally widely used for industrial and commercial purposes. At this time, Refrigeration is a tool whose role in human life today is arguably quite large. Refrigeration is used to store food ingredients, vegetables and even fruits. The research was conducted on problems or damages that occurred in refrigeration on the KM Belt Nusantara 37 ship at PT Pelni. The type of research used in this thesis is descriptive research, using a qualitative approach. Data analysis was carried out using descriptive methods, namely methods that were carried out by first collecting existing data then classified, then interpreted so as to provide solutions to problems. The 8 most common problems in the refigeration system on KM ships. Belt Nusantara 37 is a
\end{abstract}


compressor that runs but stops suddenly, Compressors start and stop too often, Compressors run continuously, Unusual noise on the compressor, High Discharge Temperature, Frost on the Evaporator, Decreased cooling ability, Less oil in the compressor.

Keywords: Refrigeration, Compressor

\section{PENDAHULUAN}

Kapal merupakan sarana transportasi yang sangat efisien. Mengikuti perkembangan zaman yang sekarang ini semakin maju dan modern serta canggih, kapal juga dirancang sedemikian sehingga dapat memenuhi kebutuhan yang diinginkan. Lancarnya kinerja dari mesin induk tidak lepas dari peran serta factor mesin pendingin (refrigeration). Refrigeration adalah sebuah alat siklus yang prinsip kerjanya hampir sama dengan mesin kalor yang menggunakan freon kerja berupa refrigerant. Siklus refrigerasi yang paling banyak dipakai adalah daur refrigeration kompresi uap yang melibatkan empat komponen dasar yaitu : kompresor, kondensor, katup ekspansi dan evaporator.

Tujuan dari refrigeration untuk menjaga ruangan tetap dingin dengan menyerap panas dari ruangan tersebut sedangkan pompa kalor adalah suatu alat yang dapat mentransfer panas dari media bertemperatur rendah ke media bertemperatur tinggi yang bertujuan untuk menjaga rungan tetap bertemperatur tinggi. Proses pemberian panas tersebut disertai dengan menyerap panas dari sumber bertemperatur rendah. Kedua alat penukar panas kalor tersebut menggunakan siklus kompresi uap.

Pengetahuan tentang prinsip kerja refrigeration, permasalahn dan karakteristik yang dimiliki oleh mesin pendingin sangatlah penting untuk diketahui oleh para taruna karena penerapannya sangatlah penting dalam pengawetan bahan makanan diatas kapal.

\section{KAJIAN LITERATUR}

\section{Pengertian Umum Refrigeration}

Refrigeration adalah produksi dan pemeliharaan tingkat suhu dari suatu bahan atau ruangan agar suhunya lebih rendah dari suhu lingkungan sekitarnya atau atmosfir dengan cara penyerapan atau penarikan panas dari bahan atau ruangan itu. Refrigeration juga dapat diartikan sebagai suatu pengelolaan terhadap panas. Refrigerasi adalah suatu proses penyerapan panas pada suatu benda dimana setiap benda akan mempunyai kandungan panas yang besarnya tergantung dari temperatur benda tersebut.

\section{Prinsip Dasar Refrigeration}

Secara umum, prinsip refrigeration adalah proses penyerapan panas dari dalam ruangan yang tertutup (kedap), lalu memindahkan serta mengenyahkan panas keluar dari ruangan tersebut. Atau dapat pula diartikan sebagai suatu sistem yang mengatur kondisi udara didalam suatu ruangan untuk mempertahankan suhu yang dikehendaki. Refrigeration memanfaatkan sifat-sifat panas (thermal) dari refrigerant selagi bahan itu berubah keadaan dari bentuk cair menjadi gas dan 
sebaliknya dari gas menjadi cair. Fungsi utama sistem refrigeration yaitu untuk mengambil panas yang tidak diperlukan dari suatu ruangan. Kemudian panas tersebut dipindahkan ke tempat lain di luar ruangan yang tidak mengganggu. Kerja tersebut dapat dilakukan dengan mengalirkan refrigerant yang bersirkulasi di dalam sistem refrigeration.

\section{Bahan Pendingin (Refrigerant)}

Bahan Pendingin (refrigerant) adalah sejenis cairan yang mempunyai titik didih sangat rendah pada tekanan satu atmosfir. Refrigerant adalah suatu zat yang mudah menguap, mudah diubah wujudnya dari gas menjadi cair atau sebaliknya dan berfungsi sebagai penghantar panas dalam sirkulasi instalasi mesin refrigeration, yaitu mengambil panas dari evaporator dan membuangnya di kondensor. Refrigerant adalah suatu zat yang dimanfaatkan sifat-sifat thermal-nya untuk menyerap panas dari produk didalam sistem refrigeration. Zat ini mempunyai titik didih yang sangat rendah pada tekanan 1 atm. Didalam sistem, refrigerant tersebut dihisap dan ditekan oleh kompresor sehingga mengalir didalam sistem refrigerasi. Disamping mengalami perubahan suhu dan tekanan akibat proses kompresi, refrigerant tersebut juga mengalami perubahan wujud dari cair ke gas dan sebaliknya. Sifat penyerapan panas yang ditimbulkan pada saat perubahan wujud itulah yang dimanfaatkan untuk kepentingan refrigeration.

4. Jenis-jenis Bahan Pendingin (Refrigerant)

Bahan pendingin (refrigerant) yang digunakan dalam refrigeration terdiri dari 2 jenis antara lain:

a. Amonia (R 717 atau $\mathrm{NH}_{3}$ )

Amonia adalah jenis refrigerant yang mempunyai banyak kelemahan diantaranya menimbulkan karat bila bercampur dengan air dan uap air, tidak larut dalam pelumas, beracun, dapat merusak mata, kulit dan paru-paru serta mudah meledak bila bercampur dengan udara yang mengandung oksigen pada perbandingan tertentu.

b. Halogen

Halogen adalah refrigerant yang 'aman' dan tidak beracun yang banyak dipakai sekarang ini, maksud 'aman' disini adalah aman bagi manusia secara langsung ketika terhisap dibandingkan dengan amonia. Adapun di pasaran dikenal dengan freon, genetron, frigen, areton, isotron, asahi frond dan lainlain. Jenis halogen ini terdiri dari : R11 (Tricloromono fluoro metane $=\mathrm{CCI}_{3} \mathrm{~F}$ ), $\mathrm{R} 12$ (Dichloro difluoro methane $=\mathrm{CCL}_{2} \mathrm{~F}_{2}$ ), $\mathrm{R} 22$ (Monochloro difluoro methane $\left.=\mathrm{CHCLF}_{2}\right)$, dan $\mathrm{R} 502\left(\right.$ Campuran antara $\mathrm{CCL}_{2} \mathrm{~F}_{2}-\mathrm{CF}_{3}=51,2 \%$ dan $\mathrm{CHCLF}_{2}=48,8 \%$.

5. Komponen Refrigeration

Berdasarkan peranannya, jenis komponen refrigeration diklasifikasikan menjadi tiga kelompok yaitu : komponen utama, komponen bantu dan komponen pengontrol.

a) Komponen Utama

1) Kompresor

Kompresor berfungsi menghisap gas refrigerant bertekanan dan bertemperatur rendah dari evaporator, selanjutnya gas yang bertemperatur dan 
bertekanan rendah dikompresikan. Tekanan dan temperatur gas refrigerant yang tinggi dari kompresor mengalir ke kondensor sehingga gas refrigerant berubah wujudnya menjadi cairan setelah mengalami proses pengembunan (kondensasi).



Gambar 1. Compressor

\section{2) Kondensor}

Kondensor berfungsi untuk merubah gas refrigerant yang bertekanan dan bertemperatur tinggi menjadi cairan refrigerant yang bertekanan tinggi dan bersuhu biasa melalui proses penyerapan panas yang disebut kondensasi. Selama proses penyerapan, panas refrigerant uap diserap melalui permukaan kondensor oleh media pendingin.

Tipe kondensor yang biasa dipakai dikapal adalah tipe shell and tube dengan media pendingin air laut sistem buangan yang di lengkapi sebuah pompa dan alat pengaman. Kecepatan aliran air pendingin sangat mempengaruhi perpindahan kalor untuk mencairkan gas refrigerant yang bertekanan dan bertemperatur tinggi di dalam kondensor.

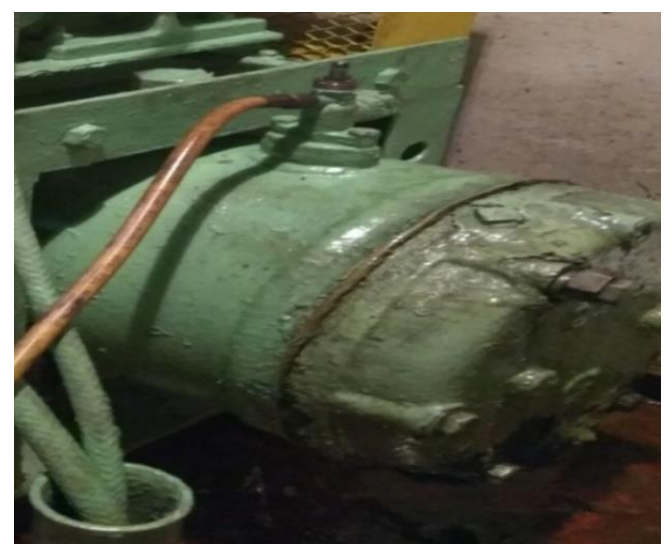

Gambar 2 Kondensor

3) Tangki Penampung (Receiver Tank)

Sebelum refrigerant disirkulasikan ke evaporator melalui katup ekspansi, refrigerant ditampung terlebih dahulu dalam receiver. Refrigerant yang 
tertampung sudah berbentuk cairan, sehingga dalam keadaan tidak beroperasi jumlah refrigerant dalam sistem dapat diketahui melalui gelas penduga (sigh glas) yang diberi skala.

Dalam Receiver kadang-kadang yang tertampung bukan hanya refrigerant cair, juga udara dan minyak pelumas. Untuk mencegah hal-hal yang tidak diinginkan receiver dilengkapi dengan katup pengaman, oil drain dan equalizer yang dihubungkan dengan kondensor.



Gambar 3 Receiver tank

\section{4) Katup Ekspansi}

Katup ekspansi berfungsi untuk mengatur jumlah refrigerant yang akan mengalir ke evaporator dan menurunkan tekanan cairan refrigerant untuk mendapatkan jatuh tekan. Jadi katup ekspansi merupakan alat untuk mengatur batasan antara tekanan tinggi dengan tekanan rendah.

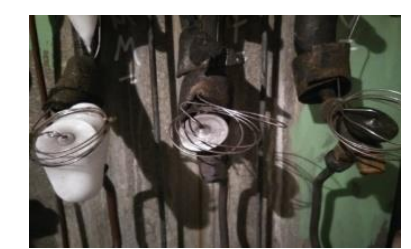

Gambar 4 Tanki ekspansi

\section{5) Evaporator}

Evaporator berada dalam ruang pendingin dan diletakkan sesuai dengan tipe yang dipakai. Sama halnya dengan kondensor, evaporator adalah bagian pemindah panas melalui permukaan yang terdiri dari plat-plat maupun koil-koil (gulungan) pendingin.

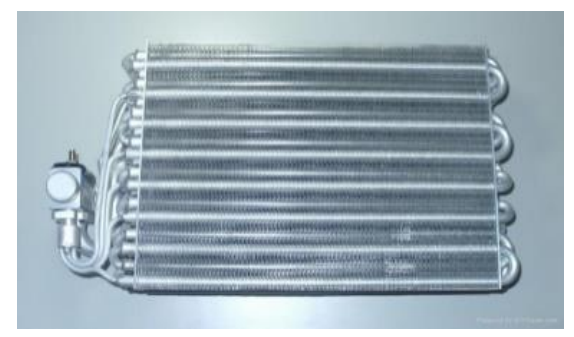

Gambar 5 Evaporator 
b) Komponen Bantu

Keberadaan komponen bantu pada refrigeration hanya sebagai alat yang membantu kelancaran aliran refrigerant pada saat bersirkulasi, oleh karena itu keberadaannya tidak mutlak. Penggunaan jenis komponen bantu di setiap refrigeration tidak selalu sama, terutama akan dipengaruhi oleh jenis refrigerant yang digunakan dan temperatur akhir yang akan dicapai.

Untuk sistem refrigeration dua tingkat (two stage) mempunyai ciri-ciri yaitu dilengkapi Intercooler/gas cooler. Alat ini dipasang diantara dua tingkat pemampatan yang berguna mendinginkan atau mengurangi superheat uap yang akan dimampatkan lagi dengan maksud agar temperatur pengeluaran akhir tidak terlampau tinggi dan untuk meningkatkan efisiensi dari kompresor tingkat kedua. Pada dasarnya, intercooler atau gas coolerialah suatu pendingin yang menggunakan cairan refrigerant untuk mendinginkan uap mampat.

Jenis kegunaan dan penempatan setiap komponen bantu pada refrigeration adalah sebagai berikut :

\section{1) Oil Separator}

Oil saparator adalah alat yang digunakan untuk memisahkan minyak pelumas kompresor dengan uap refrigerant bertekanan tinggi, alat ini ditempatkan pada saluran refrigerant antara kompresor sampai kondensor. Minyak Pelumas dalam kompresor dapat terbawa oleh uap refrigerant yang telah dimampatkan oleh kompresor, ini dapat terjadi karena Jumlah minyak pelumas dalam kompresor terlalu banyak, Ada bagian-bagian pada kompresor yang telah aus misalnya ring piston dan Tekanan penghisapan kompresor terlalu rendah.

\section{2) Filter Dryer}

Adalah suatu alat yang digunakan untuk menyerap kandungan air dan kotoran yang terkandung didalam refrigerant pada instalasi refrigeration. Alat ini merupakan suatu tabung yang didalamnya terdapat bahan pengering atau dissicant, saringan kotoran dan penahan agar bahan pengering tidak terbawa oleh aliran refrigerant yang dipasang pada kedua ujung tabung tersebut. Untuk memadatkan bahan pengering dalam tabung maka pada salah satu bagian saringannya dipasang pegas.

Filter Dryer merupakan alat bantu yang digunakan pada refrigeration dengan jenis refrigerant halogen khususnya R. 134 A. Didalam filter dryer berisi suatu bahan pengering yang disebut (Dessicant) digunakan untuk menyerap air yang dikandung refrigerant, jenis bahan pengering yang sering digunakan adalah silica gel karena mempunyai daya serap air lebih besar. Bahan pengering tersebut setelah kotor ada yang dapat diganti dan ada pula yang tidak dapat diganti tergantung dari konstruksi tabung filter dryer. Pada refrigeration alat bantu filter dryer ditempatkan di saluran cairan refrigerant tekanan tinggi yaitu saluran antara kondensor dan ekspansi.

Ada beberapa jenis Dessicant (bahan pengering) yang sering digunakan pada refrigeration, diantaranya adalah :

1. Silica Gel ( $\left.\mathrm{Si} \mathrm{O}_{2}\right)$

Jenis ini berbentuk butir-butir kecil atau kristal yang berwarna putih atau kebiru-biruan. Ciri-cirinya : 
a. Tidak dapat hancur menjadi tepung dan tidak bereaksi dengan minyak pelumas kompresor.

b. Dapat menyerap uap air tanpa merubah keadaannya.

c. Dapat menyerap air sampai $40 \%$ dari beratnya sendiri.

d. Dapat diaktifkan lagi dengan memanaskannya antara $120-250^{\circ} \mathrm{C}$ dan setelah dingin dapat digunakan kembali.

2. Activated Alumina ( $\left.\mathrm{Al}_{2} \mathrm{O}_{3}\right)$

Banyak digunakan pada AC. Ciri-cirinya adalah :

a. Berbentuk butir-butir kecil seperti kristal, tidak korosif dan tidak larut dalam air.

b. Dapat menyerap uap air tanpa merubah keadaanya.

c. Mepunyai daya serap air sampai $14 \%$ dari beratnya sendiri.

d. Dapat diaktifkan kembali dengan memanaskannya sampaim sekitar $177^{\circ}-$ $300^{\circ} \mathrm{C}$.

\section{Calcium Clorida $\left(\mathrm{Ca} \mathrm{Cl}_{2}\right)$}

Berbentuk butir-butir kecil dan tidak dapat dipasang secara permanen karena setelah menyerap uap air akan terjadi perubahan keadaan sehingga dapat mengakibatkan filter dryer menjadi buntu/ tersumbat. Jenis ini dapat menyerap air sebanyak $100 \%$ dari beratnya sendiri namun jenis ini tidak banyak digunakan.

\section{Molecular Sieve}

Jenis ini berbentuk bulat seperti lada putih dan dapat dipakai secara permanen, jenis ini juga benyak digunakan dan mempunyai daya serap yang kuat (lebih kuat dari pada silica gel), Dapat diaktifkan kembali dengan cara dipanasi sampai sekitar $200^{\circ}-300^{\circ} \mathrm{C}$.

\section{3) Akumulator}

Adalah alat untuk memisahkan cairan dan uap refrigerant yang bertekanan rendah dimana alat ini berbentuk tabung yang jenis logamnya disesuaikan dengan refrigerant. Sistem pemisahan cairan dan uap hanya berdasarkan perbedaan berat jenis. Cairan refrigerant karena berat jenisnya lebih besar akan berada pada bagian dasar sedangkan uap refrigerant akan terletak pada bagian atasnya. Pada prinsipnya akumulator merupakan tempat berbentuk tabung yang digunakan untuk memisahkan cairan/refrigerant yang tidak dapat menguap di evaporator dengan uap refrigerant bertekanan rendah, sehingga akumulator dapat pula dikatakan tempat menampung cairan refrigerant bertekanan rendah atau Low Receiver.

Akumulator pada refrigeration selalu ditempatkan pada saluran uap tekanan rendah, sesuai dengan kegunaannya maka keberadaan akumulator tersebut akan dapat menghindari terhisapnya cairan refrigerant oleh kompresor disaat pengoperasiannya.

4) Alat Penukar Panas (Heat Exchange)

Heat exchanger atau penukar kalor merupakan suatu tempat terjadinya proses pemindahan kalor dari cairan refrigerant bertekanan tinggi kepada uap refrigerant tekanan rendah. Sebagai akibatnya jumlah kandungan kalor cairan refrigerant yang akan diuapkan di evaporator akan berkurang, dengan 
keadaan demikian pada saat proses penguapannya akan memungkinkan menyerap kalor lebih banyak. Penerapan heat exchanger dapat berbentuk suatu alat bantu dengan cara hanya menyinggungkan pipa saluran cairan atau refrigerant tekanan tinggi dengan pipa saluran uap refrigerant tekanan rendah.

\section{Prinsip Kerja Refrigeration}

Pengambilan panas dari suatu benda atau zat dapat dilakukan dengan berbagai cara disebut proses pendinginan. Terjadinya pendinginan sangat dipengaruhi oleh tekanan dan temperatur. Pada refrigration sistem kompresi pendinginan terjadi karena bahan pendingin (refrigerant) dimampatkan sehingga tingkat energi uap naik, dimana tekanan dan temperatur menjadi tinggi. Selanjutnya refrigerant dikondensasikan atau didinginkan menyebabkan temperatur turun dan tekanan relative tinggi. Melalui pengatur jumlah refrigerant (katup ekspansi), refrigerant dikabutkan sehingga tekanan turun akibatnya refrigerant menyerap panas untuk menguap pada tekanan dan temperatur yang cukup rendah.

Secara garis besar siklus refrigerant dalam unit refrigeration sistem kompresi adalah sebagai berikut :

1. Kompresi

Dimana refrigerant uap dengan tekanan dan temperatur rendah dihisap kompresor dari evaporator, kemudian di dalam kompresor dimampatkan untuk mendapatkan tekanan dan temperature yang tinggi. Untuk sistem dua tingkat maka temperatur kompresi pada tekanan tinggi dicegah agar tidak terlalu tinggi (over heated) selain itu juga memperbaiki COP (Coefisient of Performence) sehingga diperoleh massa refrigerant yang besar. Setelah gas refrigerant yang keluar pada inter cooler dihisap oleh kompresor pada sisi tekanan tinggi maka gas refrigerant itu di kompresi kembali.

2. Kondensasi

Refrigerant uap yang telah dimampatkan lalu didinginkan di kondensor, sehingga terjadi kondensasi dimana refrigerant uap berubah menjadi cair dengan temperatur biasa dan tekanan masih relative tinggi.

3. Ekspansi

Jumlah refrigerant yang mengalir di perkecil untuk mendapatkan jatuh tekan dan diekspansikan yang memungkinkan refrigerant dapat menguap pada tekanan rendah di evaporator.

4. Evaporasi

Tahap terakhir dimana refrigerant menyerap panas dari sekelilingnya setelah diekspansikan (dikabutkan), sehingga terjadi pendinginan di evaporator. Secara singkatnya dapat diuraikan bahwa refrigerant di hisap kompresor dari evaporator melalui suction line, kemudian ditekan dan mengalir ke kondensor. Di kondensor terjadi kondensasi refrigerant uap menjadi cair, yang kemudian ditampung dalam receiver. Refrigerant cair kemudian mengalir ke evaporator melalui katup ekspansi dan terjadi peristiwa jatuh tekan. Dievaporator refrigerant menguap, adakalanya refrigerant tidak semuanya menguap dan terus mengalir ke akumulator. untuk mencegah kompresi cair (liquid back), refrigerant yang tidak menguap 
dialirkan kembali ke evaporator, sedang yang berbentuk uap mengalir ke kompresor untuk disirkulasikan kembali ke dalam sistem.

\section{Pedoman Pengoperasian Refrigeration}

Setiap kegiatan dalam pengoperasian unit refrigeration dilakukan secara bertahap dimana jenis tahapannya tidak selalu sama. Ini dipengaruhi oleh kelengkapan jenis komponen yang digunakan oleh refrigeration tersebut, semakin banyak jenis komponen yang digunakan maka prosedur mengoperasikannyapun akan semakin banyak pula tahapannya. Oleh sebab itu tehnik pengoperasian suatu unit refrigeration mempunyai tehnik pengoperasian yang tidak harus selalu sama.

Adapun hal-hal yang pokok dalam kegiatan pengoperasian unit refrigeration adalah sebagai berikut :

1. Persiapan Sebelum Start

Kegiatan ini dimaksud untuk mempersiapkan keadaan refrigeration untuk siap dioperasikan sehinggga dapat mencegah terjadinya hal atau keadaan yang tidak diinginkan pada saat mesin dioperasikan. Keadaan yang perlu diperhatikan adalah keadaan tenaga/ sumber penggerak mesin refrigerasi, keadaan kompresornya dan keadaan disekitar bagian-bagian refrigeration yang bergerak/ berputar.

a. Periksa keadaan sumber tegangannya.

b. Periksa keadaan baut-baut pondasi.

c. Periksa jumlah minyak pelumas kompresor.

d. Memeriksa transmisi/ kopel kompresor.

e. Memeriksa keadaan lingkungan ruang refrigeration.

2. Menjalankan Refrigeration (Start)

Untuk menjalankan refrigeration ini banyak ragamnya, namun yang terpenting adalah memastikan terbukanya saluran uap refrigerant yang bertekanan tinggi sehingga begitu kompresor bergerak maka refrigerant yang dimampatkan dapat langsung mengalir ke komponen lainnya. Selain itu perlu diperhatikan pula aliran media pendingin kompresor atau kondensor sehingga tidak akan terjadi keterlambatan proses pendinginannya dan setelah itu kemudian mengatur pembukaan kran-kran lain yang diperlukan agar refrigerant dapat bersirkulasi secara normal.

a. Buka semua kran pada saluran refrigerant bertekanan tinggi,

b. Jalankan sirkulasi media pendinginan kompresor dan kondensor,

c. Menjalankan penggerak kompresor,

d. Mengatur pembukaan katup ekspansi dan kran hisap kompresor,

e. Menjalankan tenaga penggerak perantara pendinginan.

3. Pemeriksaan Selama Refrigeration Beroperasi

Secara rutin kegiatan ini perlu dilakukan sehingga keadaan refrigeration dapat dimonitor keadaanya sehingga apabila terjadi kelainan secepatnya dapat diambil tindakan untuk perbaikannya. Adapun bagian-bagian yang perlu diperiksa antara lain adalah tekanan refrigerant, temperatur pendinginan, keadaan sumber tenaga penggerak dan lain-lain.

a. Periksa tekanan pengeluaran, penghisapan dan pelumasan kompresor.

b. Perika temperatur media pendinginan kondensor dan kompresor.

c. Periksa temperatur pendinginan dalam ruang pendinginan. 
d. Periksa keadaan sumber tenaga penggeraknya.

4. Mematikan Refrigeration (Stop)

Pada saat refrigeration terutama dalam jangka waktu yang cukup lama diharapkan refrigerant dapat tertampung dalam kondensor atau receiver tank. Untuk itu sebelum kompresor dimatikan sebaiknya kran yang mengalirkan refrigerant bertekanan tinggi dari receiver tank ditutup terlebih dahulu selanjutnya setelah tekanan penghisapan kompresor turun, tenaga penggerak kompresor dimatikan dan menutup kran penghisapan kompresor serta kran-kran lainnya.

\section{METODE PENELITIAN}

Penelitian dilakukan pada waktu penulis melaksanakan praktek laut di atas kapal, terhitung dari tanggal 25 September 2017 sampai dengan tanggal 28 September 2018. Penelitian dilakukan terhadap masalah atau kerusakankerusakan yang terjadi pada permesinan yang berada di atas kapal terutama kerusakan Refrigeration. Tempat penulisan dilakukan di atas kapal, dengan data kapal sebagai berikut :

1. Nama perusahaan

2. Nama kapal

3. Panggilan

4. Jenis kapal

5. Bendera

6. Tahun pembuatan

7. Dibuat di

8. Nomor IMO

9. Mesin penggerak utama
: PT. PELNI

: KM. SABUK NUSANTARA 37

: JZTK

: PASSENGER CARGO

: INDONESIA

$: 2012$

: PT. DAYA RADAR UTAMA

: 9712149

: MITSUBISHI Type S6R2-MPTK2

penelitian deskriptif, dengan menggunakan pendekatan kualitatif (Astriawati \& Wibowo, 2020). Penelitian deskriptif adalah suatu bentuk penelitian yang ditunjukan untuk mendeskripsikan fenomena-fenomena yang ada, baik fenomena alamiah maupun fenomena buatan manusia (Wibowo \& Astriawati, 2021). Fenomena itu bisa berupa bentuk aktifitas, karakteristik, perubahan, hubungan, kesamaan, dan perbedaan antara fenomena yang satu dengan fenomena yang lainnya.

\section{PEMBAHASAN}

8 masalah yang paling sering terjadi pada sistem refigeration di kapal KM. SABUK NUSANTARA 37 :

1. Kompressor Jalan Tapi Berhenti Tiba-Tiba.

Ketika sistem refrigeration kompressor start dan stop dengan tiba-tiba itu bisa terjadi karena alasan berikiut : 
Tabel 1. Kompressor Jalan Tapi Berhenti Tiba-Tiba.

\begin{tabular}{|c|c|}
\hline Kemungkinan Penyebab Kerusakan & Perbaikannya \\
\hline $\begin{array}{l}\text { 1. Low press. Cut-Out (berhenti) } \\
\text { bekerja }\end{array}$ & $\begin{array}{l}\text { 1. Pastikan bahwa semua suction valve pada posisi } \\
\text { terbuka, di sisi freon dengan kapasitas tepat dan } \\
\text { low press cut-out tidak rusak }\end{array}$ \\
\hline 2. Rusaknya oil press cut out & $\begin{array}{l}\text { 2. Pastikan oil press cut out bekerja dengan } \\
\text { dengan benar dan ganti jika rusak }\end{array}$ \\
\hline $\begin{array}{l}\text { 3. Defrosting timer lebih sering } \\
\text { bekerja }\end{array}$ & $\begin{array}{l}\text { 3. Jika defrosting timer sering bekerja bisa } \\
\text { menyebabkan compressor cut out, periksa dan } \\
\text { perbaiki defrosh timer }\end{array}$ \\
\hline rel & $\begin{array}{l}\text { 4. Perbaiki kebocoran dan isi oli pada level tepat } \\
\text { 5. pastikan tidak ada foaming, dan ganti oli jika } \\
\text { diperlukan }\end{array}$ \\
\hline $\begin{array}{l}\text { 5. Oli berbusa, ini bisa menyebabkan } \\
\text { berkurangnya tekanan oli }\end{array}$ & $\begin{array}{l}\text { 6. pastikan bahwa electrical motor trips bekerja } \\
\text { dengan benar }\end{array}$ \\
\hline
\end{tabular}

Sumber : KM. SABUK NUSANTARA 37

2. Compressor terlalu sering start dan stop.

Jika dalam mempertahankan temperatur settingan pada ruang pendingin, ref compressor sering cut-in dan cut-out, masalah seperti ini harus diselesaikan secepatnya, penyebabnya biasanya:

Tabel 2. Kompressor Terlalu Sering Start Dan Stop.

\begin{tabular}{|c|c|}
\hline Kemungkinan Penyebab Kerusakan & Perbaikannya \\
\hline $\begin{array}{l}\text { Kesalahan setting pada cut out. Ini } \\
\text { bisa terjadi karena (Hight Pressure) } \\
\text { cut out di set terlalu tinggi atau Low }\end{array}$ & 1. check dan ganti settingan \\
\hline $\begin{array}{l}\text { Press cut out di setting terlalu } \\
\text { rendah } \\
\text { 2. Differential setting, jarak terlalu } \\
\text { kecil. Pada low pressure (LP) cut } \\
\text { out bekerja berdasarkan start dan } \\
\text { stop pressure setting }\end{array}$ & $\begin{array}{l}\text { 2. Jika jarak setting terlalu kecil ini akan } \\
\text { menyebabkan lebih sering cut in dan cut out } \\
\text { pada compressor (ganti settingan perbesar } \\
\text { jarak start dan stop tekanan compressor). } \\
\text { 3. ganti valve yang rusak }\end{array}$ \\
\hline $\begin{array}{l}\text { 3. Kerusakan pada valve. Jika } \\
\text { discharge valve compressor bocor } \\
\text { atau solenoid valve tidak menutup } \\
\text { dengan sempurna ini akan } \\
\text { menyebabkan bervariasinya sensor } \\
\text { tekanan dan akan menyebabkan } \\
\text { lebih sering cut in dan cut out } \\
\text { compressor }\end{array}$ & $\begin{array}{l}\text { 4. Jika ini buntu maka akan menyebabkan LP } \\
\text { lebih sering cut out (Clean the filter). }\end{array}$ \\
\hline $\begin{array}{l}\text { 4. Suction filter buntu. Compressor } \\
\text { dilengkapi dengan filter pada } \\
\text { suction line }\end{array}$ & \\
\hline
\end{tabular}

Sumber : KM. SABUK NUSANTARA 37

3. Kompresor jalan terus menerus. 
Fungsi kompresor pada sistem refrigeration adalah bekerja sebagai pompa untuk mengsirkulasi freon dalam siklus pendinginan dengan tujuan mempertahankan temperatur dingin dalam ruangan dan untuk mencapai ini kompressor bisa jadi akan jalan terus menerus, jika ini terjadi dapat disebabkan antara lain :

Tabel 3. Kompresor Jalan Terus Menerus.

\section{Kemungkinan Penyebab Kerusakan Perbaikannya}

1. Bahan pendingin (Freon) tidak cukup 1. pastikan thermostatic expantion valve untuk mendinginkan evaporator bekerja normal dan bersihkan filter dalam TEV

2. Thermostat low pressure cut out tidak bekerja pada temperature/tekanan rendah

3. Bahan pendingin (Freon) kurang dalam circuit

2. set dgn tepat LP cut out pada settingan yang tepat

3. check kebocoran bahan pendingin/freon dan tambahkan bahan pendingin/freon

Sumber : KM. SABUK NUSANTARA 37

4. Suara yang tidak biasa pada kompresor.

Salah satu masalah yang paling umum di permesinan adalah suara yang tidak normal dari beberapa bagian. Ini bisa terjadi karena masalah pada komponen mechanical didalam kompresor atau karena penyebab berikut :

Tabel 4. Suara Yang Tidak Biasa Pada Kompresor.

\section{Kemungkinan Penyebab Kerusakan Perbaikannya}

1. Kapasity kontrol terlalu tinggi yang 1. kurangi kapasity kontrol setting bisa menyebabkan suara knocking selama start

2. Pastikan oil level pada level aman dan

2. Tekanan oli kurang

3. Kompressor dan aligment motor tidak 3. periksa alighment dan set motor dan tepat

4. Baut pondasi longgar kompressor satu garis tidak ada busa didalamnya. Ganti atau tambahkan oli jika diperlukan

4. pastikan pondasi dalam kondisi bagus dan semua baut dalam kondisi terikat rapat

5. Driving belt loggar

5. pastikan dan check elastisitas belt dan ganti jika longgar

Sumber : KM. SABUK NUSANTARA 37

\section{Tingginya Temperatur Discharge}

Sudah menjadi keharusan ruangan pendingin dipertahankan pada temperature yang tepat, tapi terkadang discharge temperature pada kompressor melebihi batas maximal temperatur. Masalah ini bisa terjadi karena beberapa hal antara lain : 
Tabel 5. Tingginya Temperatur Discharge

\begin{tabular}{|c|c|}
\hline Kemungkinan Penyebab Kerusakan & Perbaikannya \\
\hline 1. Tingginya temperature suction karena & 1. Pastikan TEV diset dengan cukup \\
\hline $\begin{array}{l}\text { freon kurang di sirkuit } \\
\text { Kebocoran pada discharge valve dapat } \\
\text { juga menyebabkan panas }\end{array}$ & $\begin{array}{l}\text { supply freon ke evaporator. Panas lebih } \\
\text { juga akan meningkatkan temp suction } \\
\text { dan discharge dikompressor }\end{array}$ \\
\hline 3. Kebocoran pada safety valve & 2. Ganti valve yang bocor \\
\hline $\begin{array}{l}\text { 4. By pass antara suction dan discharge } \\
\text { terbuka }\end{array}$ & $\begin{array}{l}\text { 3. Ganti safety valve } \\
\text { 4. kontrol by pass untuk menghidari hal } \\
\text { ini terjadi }\end{array}$ \\
\hline
\end{tabular}

Sumber : KM. SABUK NUSANTARA 37

6. Bunga Es pada Evaporator.

Masalah lain pada mesin pendingin adalah adanya kristal es di coil evaporator yang bisa terjadi karena :

Tabel 6. Bunga Es Pada Evaporator.

\begin{tabular}{lll}
\hline \multicolumn{2}{c}{ Kemungkinan Penyebab Kerusakan } & \multicolumn{1}{c}{ Perbaikannya } \\
\hline 1. Temperatur setting terlalu rendah & 1. $\begin{array}{l}\text { tingkatkan temperatur setting dengan } \\
\text { mengatur TEV atau sensornya }\end{array}$ \\
2. Kapasitas coil kurang & 2. $\begin{array}{l}\text { pasang coil evaporator yang lebih besar } \\
\text { check dan pastikan sistem defrosting } \\
\text { bekerja normal }\end{array}$ \\
3. Defrosting tidak bekerja & 3.
\end{tabular}

Sumber : KM. SABUK NUSANTARA 37

7. Kemampuan untuk mendinginkan yang berkurang.

Jika kemampuan refigeration untuk mendingkan ruangan berkurang dan tidak bisa mempertahankan temperatur ruang muatan atau ruang provision, Hal berikut bisa jadi penyebabnya :

Tabel 7. Kemampuan Untuk Mendinginkan Yang Berkurang.

\begin{tabular}{llll}
\hline \multicolumn{2}{c}{ Kemungkinan Penyebab Kerusakan } & \multicolumn{2}{c}{ Perbaikannya } \\
\hline 1. Tidak cukup freon dalam cirkuit & 1. & tambah freon \\
2. Ruangan tidak tertutup & 2. Check dan ganti insulation & \\
rapat/kerusakan insulation room & 3. Pastikan kapasitas ruangan tidak \\
3. Ruang diisi melebihi kapasitas & & melebihi standar \\
4. Kerusakan pada solenoid atau TEV & 4. Check valve tsb dan ganti jika rusak \\
5. Pintu ruangan yang selalu terbuka & 5. tutup rapat ruangan \\
\hline
\end{tabular}

Sumber: KM. SABUK NUSANTARA 37

8. Berkurangnya oli dalam kompressor.

Jika oil di crank case kompressor berkurang dalam waktu yang singkat. Ini mengindikasikan ada kebocoran atau peningkatan konsumsi minyak lumas bisa jadi karena hal berikut : 
Tabel 8. Berkurangnya Oli Dalam Kompressor.

\begin{tabular}{ll}
\hline Kemungkinan Penyebab Kerusakan & Perbaikannya \\
\hline $\begin{array}{l}\text { 1. Nozzle atau filter buntu } \\
\text { 2. Oil berbusa karena ada kebocoran } \\
\text { pada suction line }\end{array}$ & $\begin{array}{c}\text { 1. pastikan bahwa nozzle pada pipa kembali } \\
\text { atau filter solenoid valve bersih dan } \\
\text { tidak buntu }\end{array}$ \\
$\begin{array}{c}\text { 3. Piston ring atau liner } \text { sudah usang, ini } \\
\text { bisa menyebabkan oli ikut ke system }\end{array}$ & $\begin{array}{l}\text { 2. ganti oli dan perbaiki penyebab cairan } \\
\text { masuk ke crank case } \\
\text { 3. ganti piston ring atau liner }\end{array}$ \\
\end{tabular}

Sumber : KM. SABUK NUSANTARA 37

Pembahasan ditulis melekat dengan data yang dibahas. Pembahasan diusahakan tidak terpisah dengan data yang dibahas.

\section{PENUTUP}

\section{Kesimpulan}

Refrigeration merupakan sebuah alat siklus yang prinsip kerjanya hampir sama dengan pompa kalor yang menggunakan fluida kerja berupa (refrigrant). Daur refrigerasi yang dipakai dalam siklus adalah tipe kompresi uap yang menggunakan freon 143 A sebagai pendingin (refrigerant). Dan komponen utamanya adalah kompresor, kondensor, katup ekspansi dan evaporator. Siklus kompresi uap dipengaruhi oleh beberapa faktor antara lain entalpi, kapasitas kompresor, laju aliran masa refrigerant dan laju kalor pendingin. Laju aliran masa refrigerant ditentukan oleh daya listrik, dimana daya listrik tersebut besarnya sama dengan kapasitar kompresor. Semakin besar daya listrik semakin besar pula laju aliran massa refrigerant nya. Kapasitas kondensor dan kapasitas laju cairan kalor pendingin (kapasitas evaporator) ditentukan oleh laju aliran massa refrigerant. Semkin besar laju aliran massa maka semakin besar pula kapasitas kondensor dan evaporator. COP (Coefficient Of Performance) merupakan hasil bagi antara perubahan entalpi di evaporator dengan perubahan entalpi di kompresor. COP akan semakin besar jika perubahan entalpi di evaporator semakin besar. Banyak hal yang harus selalu diperhatikan dalam perawatan refrigeration pada kapal supaya kapal tetap bisa beroperasi dengan baik.

\section{DAFTAR PUSTAKA}

AMSS. (2011). Pedoman Penulisan Laporan Tugas Akhir. Akademi Maritim Sapta Samudra Padang:AMSS.

Astriawati, N., \& Wibowo, W. (2020). Perawatan Sistem Pendingin Mesin Diesel Pada Whell Loader Komatsu Wa120-3cs. Jurnal Teknovasi: Jurnal Teknik Dan Inovasi, 7(2), 76-85.

Direktorat Jenderal Perkapalan. (2005). Statistik Ekspor Hasil Perikanan, Jakarta. Handoko. (1981). Teknik Lemari Es. PT. Ictiar Baru, Cetakan II, Jakarta. Hartanto. B. (1986). Mesin Pendingin Bidang Perkapalan I. Jakarta. Ilyas, S. (1983). Teknologi Refrigrasi Hasil Perikanan Jilid I. Badan Peneliti dan Pengembangan Pertanian. 
Ilyas, S. (1993). Teknologi Refrigrasi Hasil Perkapalan Jilid II. Badan Peneliti dan Pengembangan Pertanian.

Maimun. (2004.) Manajemen Pengoperasian dan Perawatan Mesin Pendingin. Sekolah Tinggi Perikanan. Jakarta.

Moelyanto. (1992). Pengawetan dan Pengolahan Makanan. Penebar Swadaya, Jakarta.

Sunarman dkk. (1977). Mesin Pendingin, Friga Jakarta.

Wibowo, W., \& Astriawati, N. (2021). Sistem Pendingin Tertutup Pada Mesin Diesel Tipe Diesel MAK 8M32 Sebagai Penggerak Utama Kapal Motor LIT ENTERPRISE. Jurnal POLIMESIN, 19(1), 28-34. 